\title{
Polarizabilities and Orientational Order Parameter in N-(p-n-Ethoxybenzylidene)- p-n-Alkoxy Anilines, 20.0m LC Compounds
}

\author{
Putcha Srinivasa Sastry1,2, Chintalapati Srinivas², Pokkunuri Pardhasaradhi ${ }^{3}$, \\ Venkata Gopala Krishna Murthy Pisipati ${ }^{*}$ \\ ${ }^{1}$ Department of Physics, Krishna University, Machilipatnam, India \\ ${ }^{2}$ Department of Physics, A. L. College, Vijayawada, India \\ ${ }^{3}$ Liquid Crystal Research Centre, Department of Electronics and Communications Engineering, \\ Koneru Lakshmaiah University, Vaddeswaram, India \\ Email: *vgkmpisipati@gmail.com
}

Received 29 June 2016; accepted 25 July 2016; published 28 July 2016

Copyright (C) 2016 by authors and Scientific Research Publishing Inc.

This work is licensed under the Creative Commons Attribution International License (CC BY). http://creativecommons.org/licenses/by/4.0/

(c) () Open Access

\begin{abstract}
n.m, n.Om, n0.m and n0.0m compounds play an important role in the fundamental and applied aspects. As a part of our systematic studies of the above homologous series regarding the synthesis, characterization and phase transition studies, here the authors report the polarizabilities and orientational order parameter, $S$ in N-(p-n-ethoxybenzylidene)-p-n-alkoxy anilines, $20.0 \mathrm{~m}$ with $\mathrm{m}=$ 3 to 10 liquid crystalline compounds except with $m=5$ which has been already published. The rest of the compounds exhibit the nematic LC phase except with $\mathbf{m}=\mathbf{1 0}$ which shows the smectic-C phase along the nematic phase which is originally not detected by Godzwon et al. But the author's observations with TM and differential scanning calorimeter have shown the existence on SmC phase in addition to nematic phase. Further, SmC is clarified using the histogram technique whose details are given below and are published elsewhere. The orientstonal order parameter, $S$ is estimated using different methods and compared with the value obtained from birefringence, $\delta n=\left(n_{e}-n_{o}\right)$ where no field model is used. It is observed in these compounds case as in other LC compounds Vuks isotropic model is favored compared to that of anisotropic model proposed by Neugebauer.
\end{abstract}

\section{Keywords}

Orientstonal Order Parameter, $S, 20.0 \mathrm{~m}$ LC Compounds, Vuks Isotropic Model, Neugebauer Anisotropic Model, Nematic Phase

\footnotetext{
${ }^{*}$ Corresponding author.
}

How to cite this paper: Sastry, P.S., Srinivasu, Ch., Pardhasaradhi, P. and Pisipati, V.G.K.M. (2016) Polarizabilities and Orientational Order Parameter in N-(p-n-Ethoxybenzylidene)-p-n-Alkoxy Anilines, 20.Om LC Compounds. Journal of Surface Engineered Materials and Advanced Technology, 6, 134-148. http://dx.doi.org/10.4236/jsemat.2016.63013 


\section{Introduction}

Optical and dielectric anisotropic studies on liquid crystals will provide information regarding their viability to be used in applications or not. Optical studies and the birefringence have been obtained in a number of liquid crystals [1]-[7] recently and obtained the order parameter both directly from birefringence following the procedure adopted by Kuczynski et al. and from polarizabilities by using different techniques. The advantage in first method is that the orientational order parameter, $S$ can be calculated in smectic phase also provided that the refractive indices are also obtained in the smectic phases. This is not possible in the later case as particular type of internal field has to be chosen in the nematic phase along with density values. At present there are two models available due to Vuks [8] and Neugebauer [9]. Vuks proposed an isotropic model while Neugebauer considered the nematic phase as anisotropic. Both the models will provide the polarizabilities $\alpha_{e}$ and $\alpha_{o}$ and thereby $\delta \alpha$ the polarizability anisotropy experimentally. In the perfect order (in the crystalline state) the anisotropy can be obtained semi empirically by following Lippincott and vibrtional methods. Then the order parameter, $S$ is given by $\delta \alpha / \Delta \alpha$.

The systematic studies on these compounds show that the order parameter, $S$ obtained from the Vukas model is more favorable to explain the nematic phase with few exceptions [10].

This paper presents the refractive index results with temperature and the evaluation of $\delta \alpha$ and $\Delta \alpha$ in number of LC compounds of the homologous series, N-(p-n-ethoxybenzylidene)-p-n-alkoxy anilines, 2O.Om where $\mathrm{m}=3$, 4 and 6 to 10 . The one with $\mathrm{m}=5$ is already published [11].

\section{Experimental}

The present compounds are synthesized following the established procedure reported in the literature [11]. The respective $p-n$ ethyloxy benzaldehyde and the corresponding alkoxy anilines are taken in equi-molar proportions in absolute ethanol and refluxed for four hours in the presence of few drops of glacial acetic acid. The glacial aetic acid acts as catalyst. After refluxing the reactions for four hours, the solvent was removed by distillation under reduced pressure. The crude sample was subjected to repeated recrystallization from absolute ethanol in cold to give the pure compound, until the transition temperatures are constant.

The molecular formula of the compounds is given below.

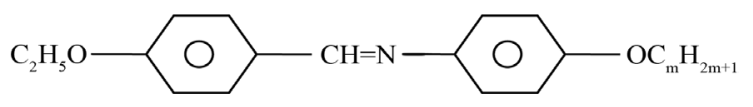

where $\mathrm{m}=3$ to 4 and 6 to 10 .

The refractive indices of all LC compounds are measured using a modified spectrometer. The temperature accuracy is $\pm 0.1^{\circ} \mathrm{C}$. The refractive indices $n_{e}$ and $n_{o}$ are measured at wavelength $589 \mathrm{~nm}$. These are measured with a wedge-shaped glass cell, similar to the one used to obtain birefringence by Haller et al. [12] A wedgeshaped glass cell was formed with two optically flat rectangular glass plates (50 $\mathrm{mm} \times 25 \mathrm{~mm})$ sandwiched with glass plate $(0.4 \mathrm{~mm})$ which acts as a wedge spacer. The optical flats are uniformly rubbed along the short edge to get the alignment of the LC molecule. The cell is filled with the LC material in the isotropic phases. The nematic LC in the cell acts as a uniaxial crystal with its optic axis parallel to the edge of the spacer glass plate. The temperature accuracy of the heating block was $\pm 0.1^{\circ} \mathrm{C}$. The accuracy in the measured refractive indices was \pm 0.0005 . The refractive index in the isotropic phase $\left(n_{\text {iso }}\right)$ shows a very nominal increment with decrease of temperature. At the isotropic-nematic (IN) phase transformation, the isotropic ray splits into two rays which indicates the onset of birefringence, one value higher and another lower than the isotropic value corresponding to extraordinary $\left(n_{e}\right)$ and ordinary refractive $\left(n_{o}\right)$ indices, respectively. This is clearly observed in the telescope of the modified spectrometer at the angle of minimum deviation. In the nematic region, $n_{e}$ increases and no decreases with decrease of temperature. The transition temperatures along with the enthalpy values are given in reference [13].

\section{Results and Discussion}

\subsection{Optical Birefringence Studies (Refractive Indices $\boldsymbol{n}_{e}$ and $\boldsymbol{n}_{o}$ ) in $20.0 \mathrm{~m}$ Compounds}

The refractive indices of $20.0 m$ liquid crystals are measured using the modified spectrometer (the details are described in the experimental section) and a wedge shaped cell. The temperature accuracy is $\pm 0.1^{\circ} \mathrm{C}$. This is clearly shown in Figure 1 and Figure 2 for the case of 20.09 and 20.010 respectively. 


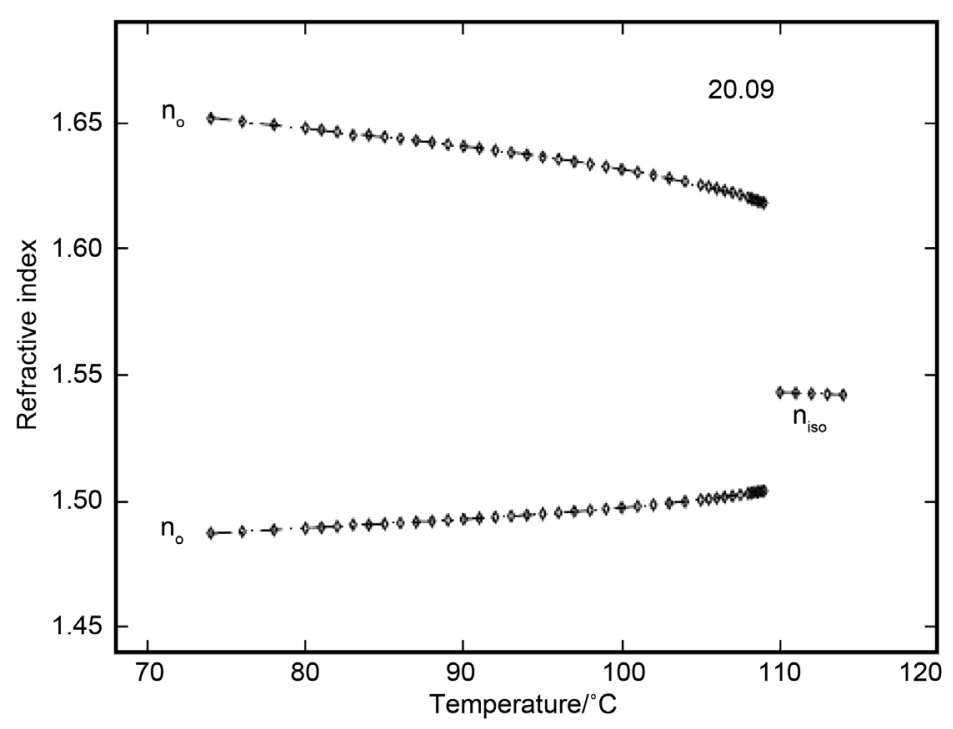

Figure 1. Variation of $n_{e}$ and $n_{o}$ with temperature in 2O.O9.

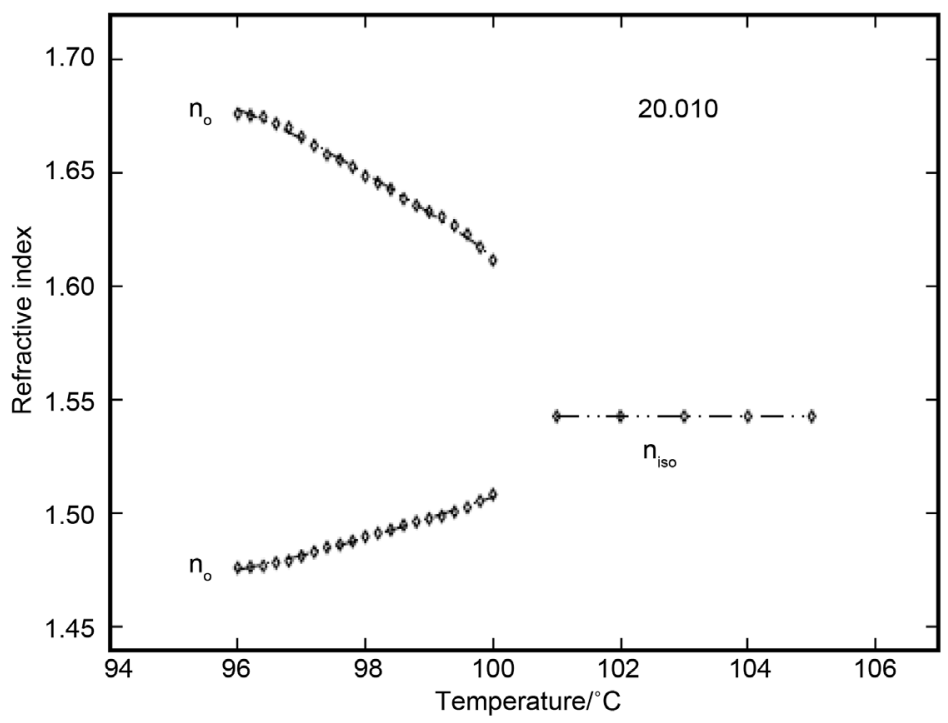

Figure 2. Variation of $n_{e}$ and $n_{o}$ with temperature in 2O.O10.

The refractive indices variations with temperature in the isotropic and nematic phases are illustrated in Figure 1 and Figure 2 for the compounds $2 \mathrm{O} . \mathrm{O} 9$ and $2 \mathrm{O} . \mathrm{O} 10$ as representative cases respectively. The IN transition temperatures observed in the birefringence measurements are in agreement with those observed in density measurements. In the case of all compounds $\delta n=\left(n_{e}-n_{o}\right)$ with reduced temperature is shown in Figure 3. Further, it is observed in the case of 20.010 the refractive indices could not be measured in smectic-C phase as the splitting has a hazy appearance and the splitting could not be detected.

\subsection{Estimation of Order Parameter}

The orientational order parameter $S$ is evaluated using different methods for all the compounds viz.

1) $S$ calculated using polarizability anisotropy calculated by Lippincott $\delta$-function method and the molecular polarizabilities obtained from Vuks model.

2) $S$ calculated using polarizability anisotropy calculated by Lippincott $\delta$-function method and the molecular polarizabilities obtained from Neugebauer model.

3) $S$ calculated using polarizability anisotropy calculated using molecular vibration method and the molecular 


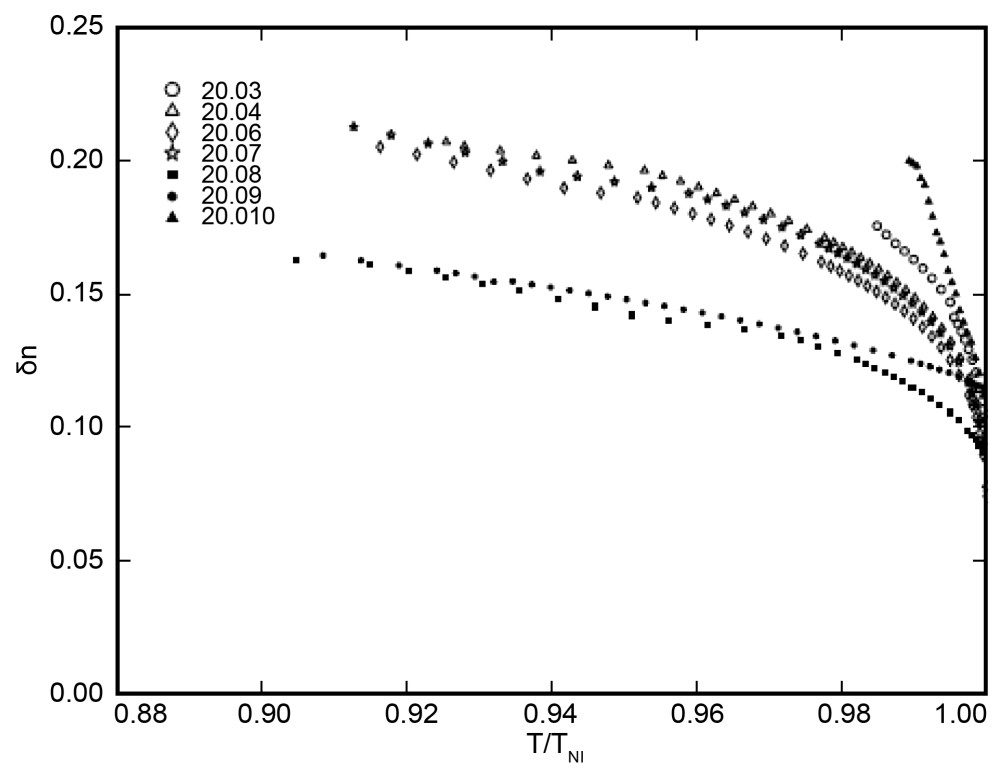

Figure 3. Variation of $\delta n$ with the reduced temperature in 2O.Om materials.

polarizabilities obtained using Vuks model.

4) $S$ calculated using polarizability anisotropy calculated using molecular vibration method and the molecular polarizabilities obtained using Neugebauer model.

5) $S$ calculated using Vuks scaling factor, and

6) $S$ calculated using Neugebauer $f(B)$ parameter.

These values are compared with that $S$ value calculated from $\delta$, birefringence.

\subsection{Estimation of Order Parameter " $S$ " from Polarizabilities}

For the estimation of the order parameter $S$ from the molecular polarizabilities $\alpha_{e}$ and $\alpha_{o}$ the following equation is used

$$
S=\left(\alpha_{e}-\alpha_{o}\right) /\left(\alpha_{\|}-\alpha_{\perp}\right)
$$

where $\alpha_{\|}$and $\alpha_{\perp}$ are the principal polarizabilities and they can be estimated using different methods including the semi empirical methods due to Lippincott and molecular vibration techniques [14] [15]. The two methods are well described. For the sake of compactness the whole procedures are not described here. Further, the molecular anisotropy can be obtained from the Haller extrapolation technique using the experimentally evaluated molecular polarizabilities from refractive index and density data. The molecular polarizabilities $\alpha_{e}$ and $\alpha_{o}$ are evaluated assuming a local field that the nematic molecule experiences. Vuks [8] and Neugebauer [9] proposed two different types of local fields. According to Vuks the nematic molecule experiences an isotropic field while Neugebauer proposed an anisotropic field to the nematic molecule. The methods used, the expressions employed and the procedures adopted are described below in each case for a ready reference.

\subsection{Estimation of Molecular Polarizabilities from Refractive Indices and Density}

The extraordinary $\left(\alpha_{e}\right)$ and ordinary $\left(\alpha_{o}\right)$ polarizabilities corresponding to the electric vector parallel and perpendicular to the optic axis are given as

$$
\begin{aligned}
& \alpha_{e}=\bar{\alpha}+2\left(\alpha_{\|}-\alpha_{\perp}\right) s / 3 \\
& \alpha_{o}=\bar{\alpha}-\left(\alpha_{\|}-\alpha_{\perp}\right) s / 3
\end{aligned}
$$

where $S$ is the order parameter $\alpha_{\|}$and $\alpha_{\perp}$ are polarizabilities of the molecule parallel and perpendicular to the long molecular axis of the liquid crystal molecule. The average molecular polarizability $\bar{\alpha}$ is given as 


$$
\bar{\alpha}=\left(\alpha_{e}+2 \alpha_{o}\right) / 3=\left(\alpha_{\|}+2 \alpha_{\perp}\right) / 3
$$

Combining the above two equations $S$, the order parameter is

$$
S=\left(\alpha_{e}-\alpha_{o}\right) /\left(\alpha_{\|}-\alpha_{\perp}\right)
$$

For the estimation of the molecular polarizabilities of liquid crystal molecules, the authors have considered both the models, one due to Vuks which considers the local field of the molecule as isotropic and the other due to Neugebauer which considers the local field as anisotropic. The relevant equations of the two models for the calculation of molecular polarizabilities are given below.

\subsubsection{Vuks Method}

This model was first applied to liquid crystal molecules by Chandrasekhar et al. [16] assuming the internal field as isotropic even in anisotropic crystal. These assumptions lead to the following equations.

$$
\begin{aligned}
& \alpha_{e}=\left[\frac{3}{4 \pi N}\right]\left[\frac{n_{e}^{2}-1}{\bar{n}^{2}+2}\right] \\
& \alpha_{o}=\left[\frac{3}{4 \pi N}\right]\left[\frac{n_{o}^{2}-1}{\bar{n}^{2}+2}\right]
\end{aligned}
$$

where $N$ is the number of molecules per unit volume, $n_{e}$ and $n_{o}$ are the extraordinary and ordinary refractive indices of the liquid crystal molecule.

$$
\bar{n}^{2}=\left[\frac{n_{e}^{2}+2 n_{o}^{2}}{3}\right]
$$

and $N=N_{A} \rho / M$ where $N_{A}$ is the Avogadro number, $\rho$ is the density and $M$ is the molecular weight.

\subsubsection{Neugebauer Method}

Subramanyam et al. [17] applied this method to liquid crystal molecule. According to this method the molecular polarizabilities are

$$
\begin{gathered}
\alpha_{e}=\left(A B-3 \pm \sqrt{(A B-3)^{2}-4 A B}\right) / 2 A \\
\alpha_{o}=\left(A B+3 \pm \sqrt{(A B+3)^{2}-16 A B}\right) / 4 A
\end{gathered}
$$

where

$$
\begin{gathered}
A=\frac{1}{\alpha_{e}}+\frac{2}{\alpha_{o}}=\frac{4 \pi N}{3}\left[\frac{n_{e}^{2}+2}{n_{e}^{2}-1}\right]+\left[\frac{2\left(n_{o}^{2}+2\right)}{n_{o}^{2}-1}\right] \\
B=\left(\alpha_{\|}+2 \alpha_{\perp}\right)=\left(\alpha_{e}+2 \alpha_{o}\right)=3 \alpha=9\left(\bar{n}^{2}-1\right) /\left[\left(4 \pi N_{i}\right)\left(\bar{n}^{2}+2\right)\right]
\end{gathered}
$$

$N_{i}$ is the number of molecules per unit volume in the isotropic phase.

Using the two models the molecular polarizabilities, $\alpha_{e}$ and $\alpha_{o}$ of all the liquid crystals are evaluated from the birefringence, $\delta n=\left(n_{e}-n_{o}\right)$ and density.

The two methods (Lippincott and vibrational) are used to estimate the polarizability components as well as mean polarizabilities for the 2O.Om compounds and the values are given in Table 1.

\subsection{Estimation of Order Parameter, $S$ from Haller's Extrapolation, Scaling Factor (Vuks) and $f(B)$ Parameter (Neugebauer)}

The corresponding expressions are given below. 
Table 1. Parallel, perpendicular components and mean polarizabilities of $70.0 \mathrm{~m}$ compounds $\left(10^{-24} \mathrm{~cm}^{3}\right)$.

\begin{tabular}{|c|c|c|c|c|c|c|c|c|}
\hline \multirow{2}{*}{ Compound } & \multicolumn{4}{|c|}{ Vuks } & \multicolumn{4}{|c|}{ Neugebauer } \\
\hline & Lip. & Vib. & Hal. & SC & Lip. & Vib. & Hal. & $\mathrm{F}(\mathrm{B})$ \\
\hline 20.03 & -13.28 & $\underline{-8.15}$ & -7.34 & -13.61 & -11.09 & -6.14 & -6.87 & 5.56 \\
\hline 20.04 & $\underline{-2.40}$ & $\underline{1.28}$ & $\underline{5.04}$ & $\underline{-3.01}$ & $\underline{1.90}$ & $\underline{5.42}$ & $\underline{7.42}$ & 14.74 \\
\hline 20.06 & $\underline{3.21}$ & $\underline{5.44}$ & $\underline{6.36}$ & $\underline{2.39}$ & -1.14 & -1.14 & $\underline{-2.21}$ & 21.46 \\
\hline 20.07 & $\underline{-0.37}$ & $\underline{1.39}$ & $\underline{4.22}$ & $\underline{-0.98}$ & -2.09 & $\underline{-4.48}$ & $\underline{-0.31}$ & 19.33 \\
\hline 20.08 & 12.71 & 13.73 & $\underline{7.55}$ & 12.85 & $\underline{-5.93}$ & $\underline{-4.59}$ & -4.71 & 27.00 \\
\hline 20.09 & 26.98 & 27.34 & 23.18 & 27.59 & 10.44 & 10.81 & 12.48 & 39.28 \\
\hline 20.010 & $\underline{-9.46}$ & -9.49 & -3.74 & -7.50 & -18.04 & -18.06 & -11.87 & $\underline{9.01}$ \\
\hline
\end{tabular}

\subsubsection{Vuks Method}

The order parameter is given by [18] [19]

$$
S=\left[\frac{\alpha}{\alpha_{\|}-\alpha_{\perp}}\right]\left[\frac{n_{e}^{2}-n_{o}^{2}}{\bar{n}^{2}-1}\right]
$$

where

$$
\bar{n}^{2}=\left(\frac{n_{e}^{2}+2 n_{o}^{2}}{3}\right)
$$

\subsubsection{Neugebauer Method}

In the Neugebauer method [18] [20] the order parameter $S$ is given

$$
S=\left[\frac{\alpha}{\left(\alpha_{\|}-\alpha_{\perp}\right)}\right] f(B)
$$

where

$$
f(B)=\left(\frac{9}{4 B}\right)\left[\left(B^{2}-\left(\frac{10}{3}\right) B+1\right)^{1 / 2}+\frac{B}{3}-1\right]
$$

and

$$
B=\frac{n^{2}-1}{n^{2}+1}\left(\frac{n_{e}^{2}+2}{n_{e}^{2}-1}+2 \frac{n_{o}^{2}+2}{n_{o}^{2}-1}\right)
$$

The scaling factors for the determination of order parameter are obtained in both the cases by plotting log-log plots between $\left[\frac{n_{e}^{2}-n_{0}^{2}}{\bar{n}^{2}-1}\right]$ and $f(B)$ in Vuks and Neugebauer cases respectively against $\left(T_{C}-T\right) /\left(T_{C}-T_{N C / N K}\right)$ i.e., the reduced temperature.

These two methods (Lippicott $\delta$-function and vibrational) are used to evaluate the polarizability anisotropy components as well as mean polarizabilities for the $20.0 m$ compounds and the values are given in Table 2 and Table 3.

The order parameter, $S$ from the molecular polarizabilities is estimated by assuming Vuks and Neugebauer internal field models. Figures 4-10 represent the variation of order parameter, $S$ with the reduced temperature for all the compounds using the two field models ((a) Vuks and (b) Neugbauer) and the values are compared with the value that is obtained either from $\delta n$ or $\alpha_{g}$ which are identically equal to one another. 
Table 2. Values of $\Sigma \mathrm{b}_{\mathrm{L}}, \Sigma \mathrm{b}_{\mathrm{T}}$ and $\left(\Sigma \mathrm{b}_{\mathrm{L}}-\Sigma \mathrm{b}_{\mathrm{T}}\right)$.

\begin{tabular}{ccccc}
\hline & & & & \multicolumn{2}{c}{ Vibrational method } \\
\cline { 2 - 4 } Compound & $\alpha_{\|}^{*}$ & $2 \alpha \perp$ & $\alpha \mathrm{M}$ \\
\cline { 2 - 4 } 20.03 & $10^{-24} \mathrm{~cm}^{3}$ & $10^{-24} \mathrm{~cm}^{3}$ & $10^{-24} \mathrm{~cm}^{3}$ & $10^{-24} \mathrm{~cm}^{3}$ \\
20.04 & 65.30 & 39.99 & 35.10 & 35.69 \\
20.06 & 68.95 & 42.13 & 37.03 & 37.66 \\
20.07 & 76.25 & 46.41 & 40.89 & 41.60 \\
20.08 & 79.90 & 48.55 & 42.82 & 43.57 \\
20.09 & 83.54 & 50.70 & 44.75 & 45.54 \\
20.010 & 87.19 & 52.84 & 46.68 & 47.51 \\
\hline
\end{tabular}

$n$ value (1.09) included in parallel component of polarizability.

Table 3. Percentage of deviations of order parameter, $S$ estimated assuming the two field models, using different methods from that obtained using $\delta$, the birefringence in $20.0 m$ compounds.

\begin{tabular}{cccc}
\hline & \multicolumn{1}{c}{$\Sigma \mathrm{b}_{\mathrm{L}}$} & $\Sigma \mathrm{b}_{\mathrm{T}}$ & $\Sigma \mathrm{b}_{\mathrm{L}}-\Sigma \mathrm{b}_{\mathrm{T}}$ \\
\cline { 2 - 3 } 20.03 & $10^{-24} \mathrm{~cm}^{3}$ & $10^{-24} \mathrm{~cm}^{3}$ & $10^{-24} \mathrm{~cm}^{3}$ \\
20.04 & 53.36 & 26.86 & 26.50 \\
20.06 & 56.22 & 28.38 & 27.84 \\
20.07 & 61.94 & 31.42 & 30.52 \\
20.08 & 64.80 & 32.94 & 31.86 \\
20.09 & 67.66 & 34.48 & 33.19 \\
20.010 & 70.52 & 36.00 & 34.52 \\
\hline
\end{tabular}

\section{Conclusions}

The refractive index and density are measured with the temperature in all the compounds of 2O.Om homologues. It is found from density measurements the isotropic nematic transition is of first order as expected and the nematic SmC phase in 20.010 compound also exhibited first order. A table has been prepared which provides the percentage of deviation of $S$ value from all the methods to that calculated from $\Delta n$, the birefringence in perfect order. (The error in the value of $S$ from $\Delta n$ is about $10 \%$ ). If the deviation is $\leq 10 \%$, the values are underlined so that they can be considered in agreement with $S$ from $\Delta n$.

The salient features observed from the results are:

1) From Figures 4-10 no preference can be given to any field model unlike the case of other liquid crystal compounds [7]. The positive values in Table 3 depict the higher value of $S$ obtained from $\delta n$, the birefringence.

2 ) Except in the case of compounds 20.03 and 20.010 the value calculated from $f(B)$ is very much smaller and is the similar case with other LC compounds [7].

3) Surprisingly, the compound 20.09 is not accepting the two models and the $S$ values calculated using the two models are very much smaller when compared to $S$ from $\delta$.

4) In the case of compounds 20.04, 20.06 and 20.07 except the cases of $f(B)$ parameter, the deviations of $S$ value are small.

5) One thing can be stated that the $f(B)$ parameter needs some fine tuning, to have $S$ values similar to that obtained from the field models and from $\delta$ n and $\alpha_{g}$. 


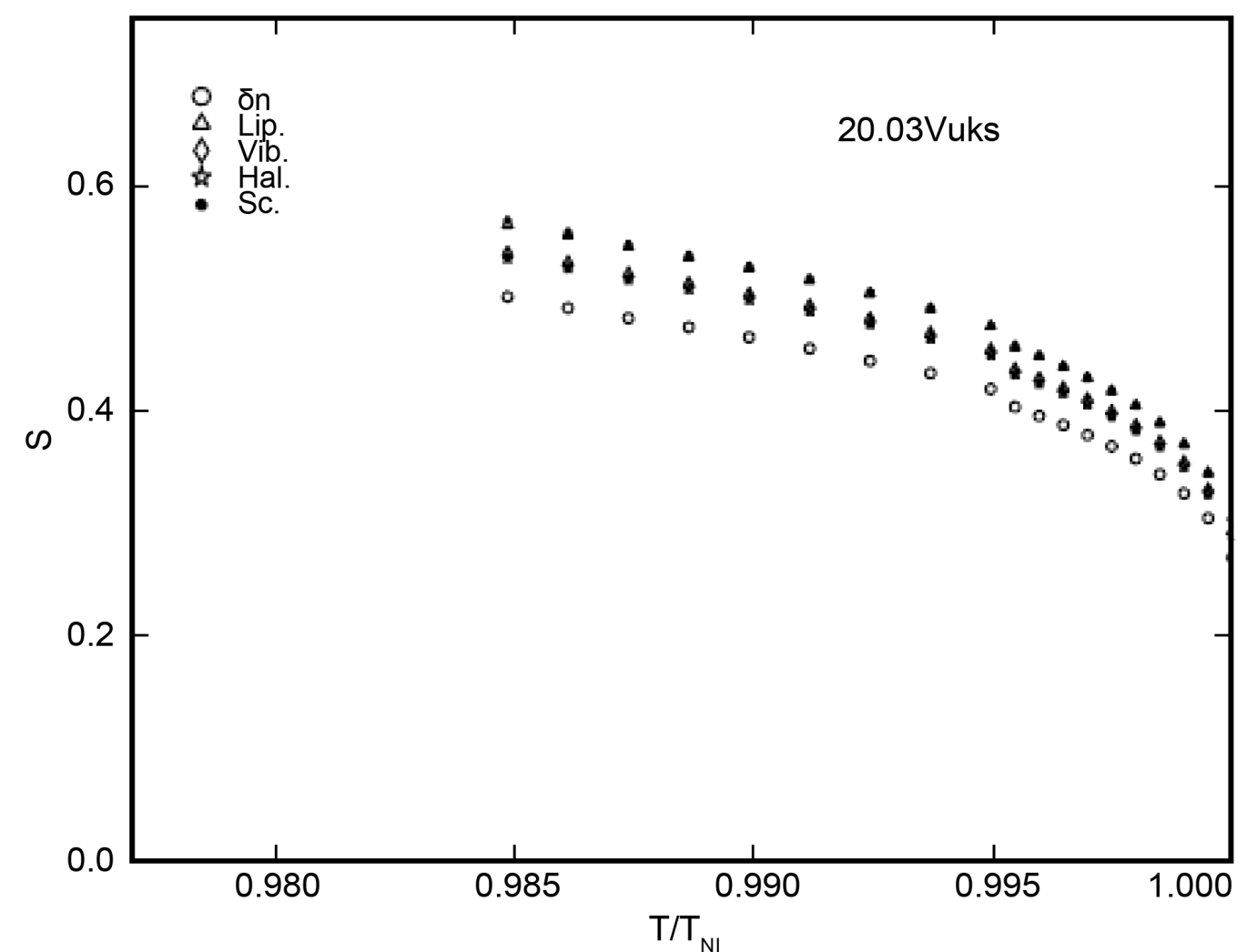

(a)

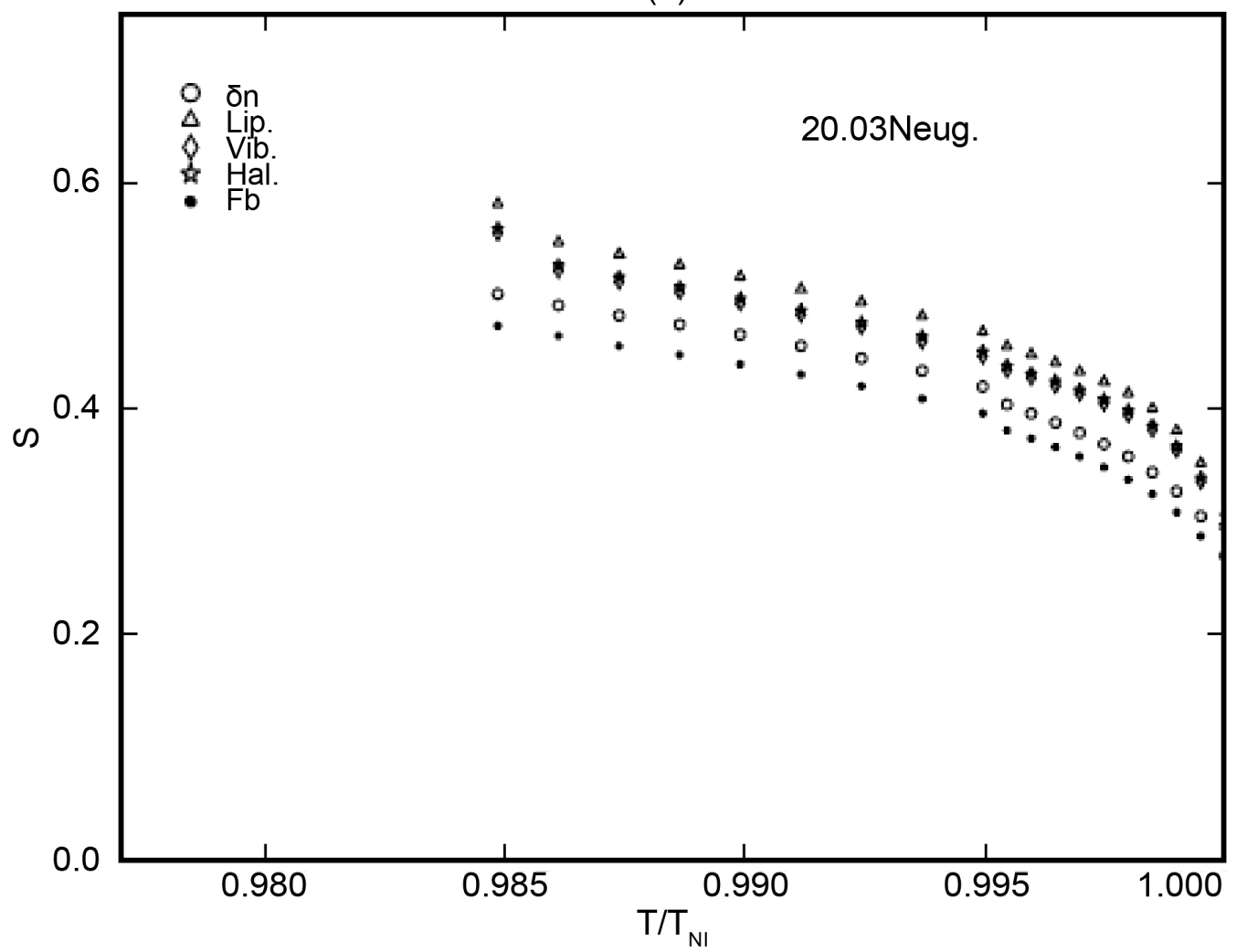

(b)

Figure 4. (a) (b) Variation of order parameter with the reduced temperature in 2O.O3. 


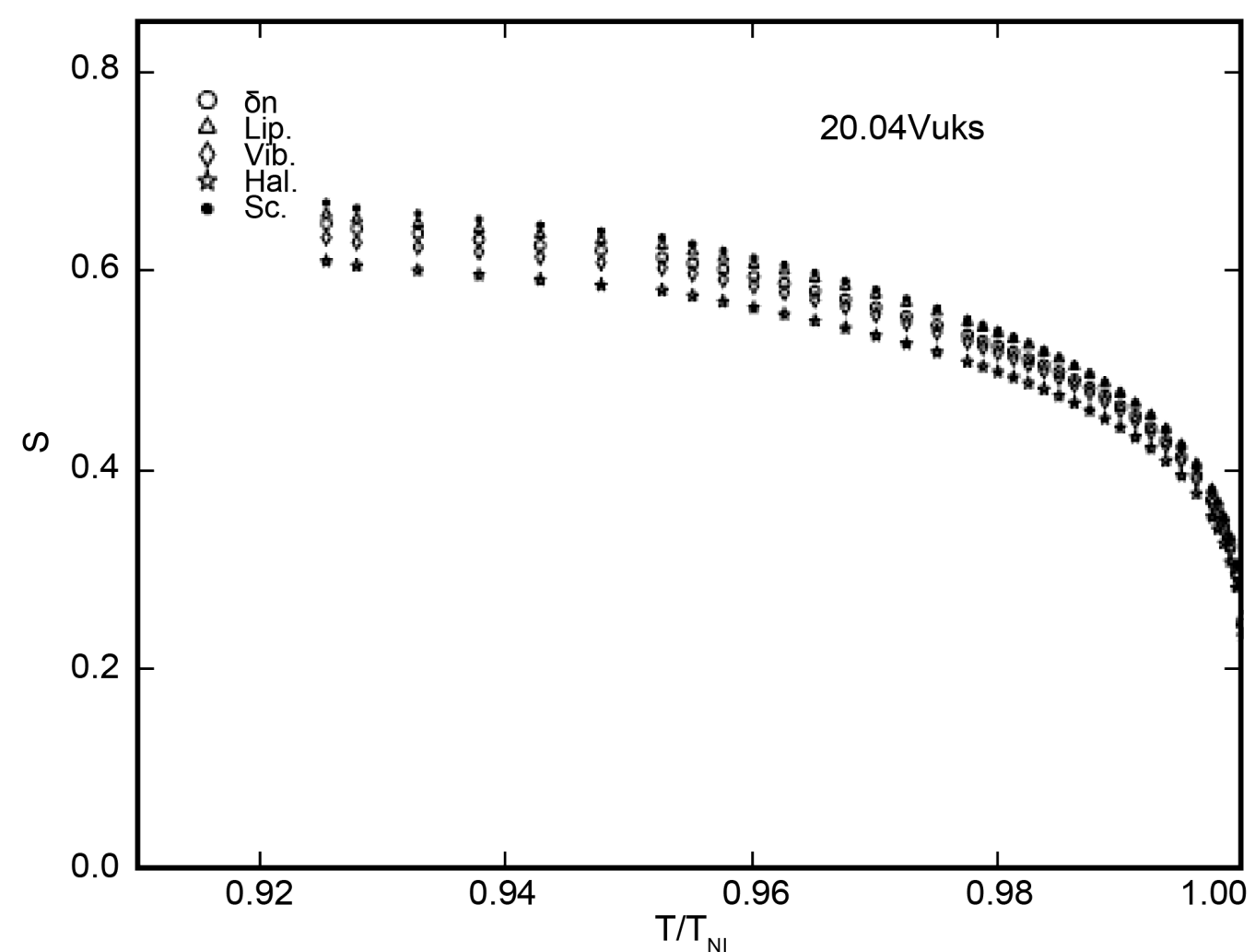

(a)

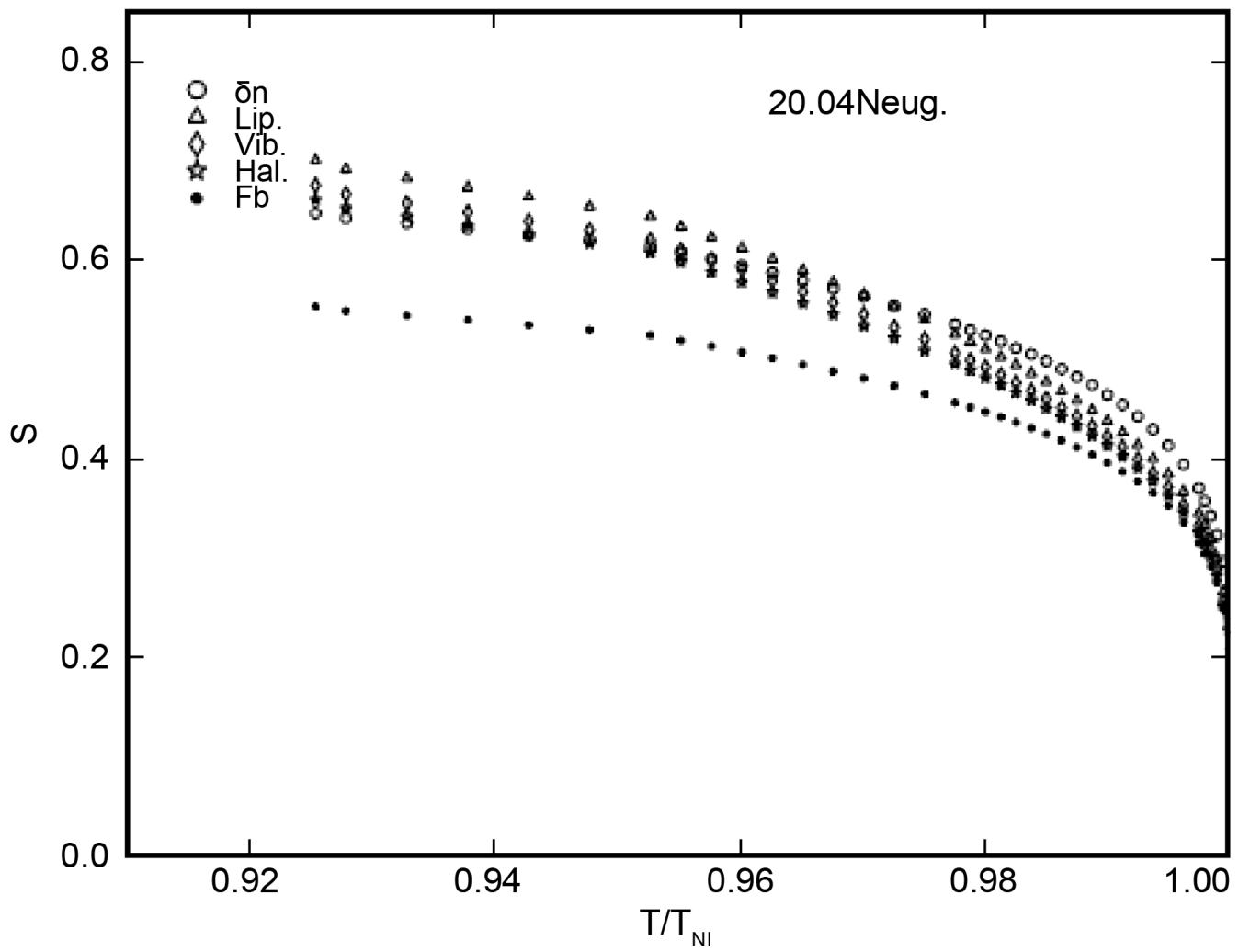

(b)

Figure 5. (a) (b) Variation of order parameter with the reduced temperature in 2O.O4. 


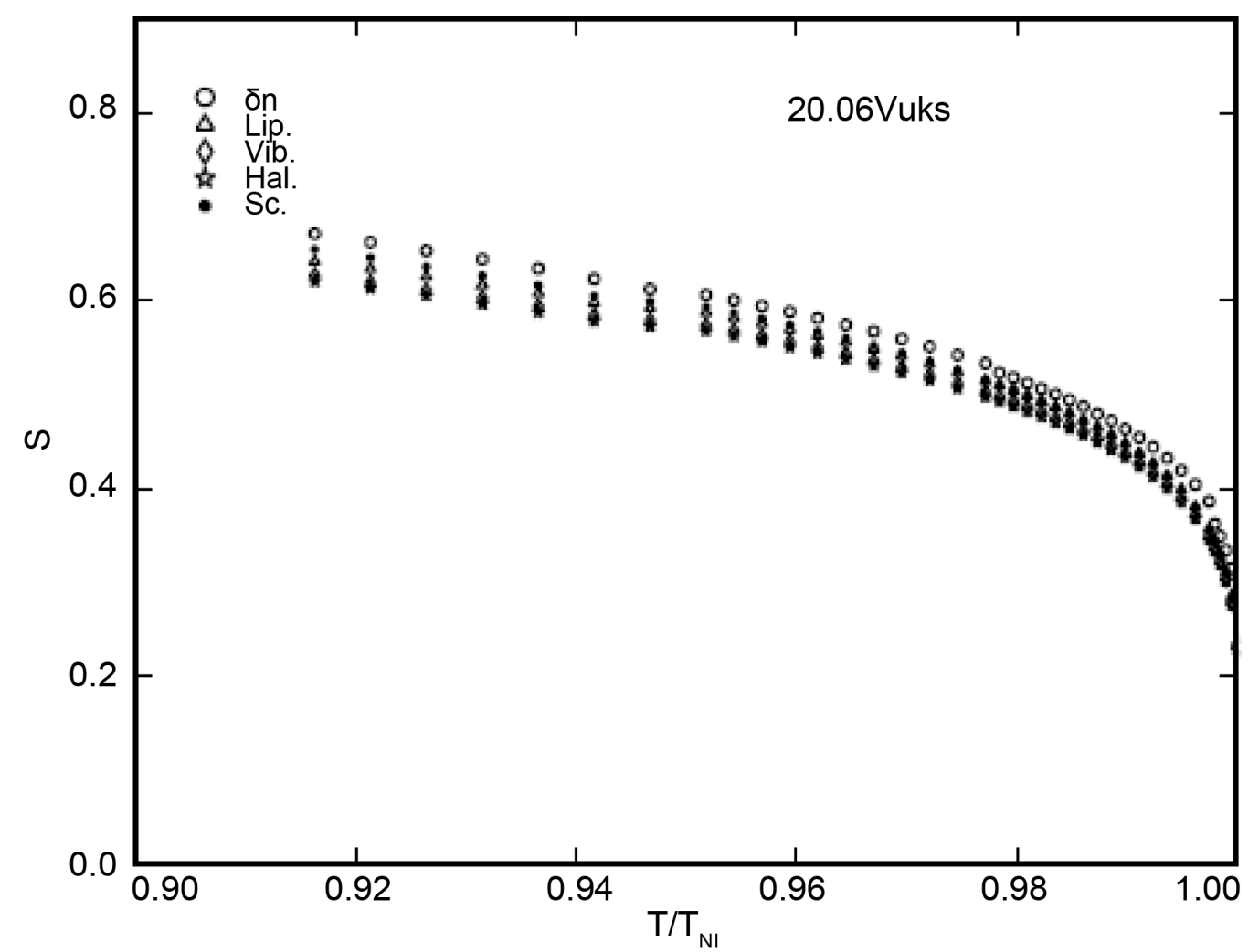

(a)

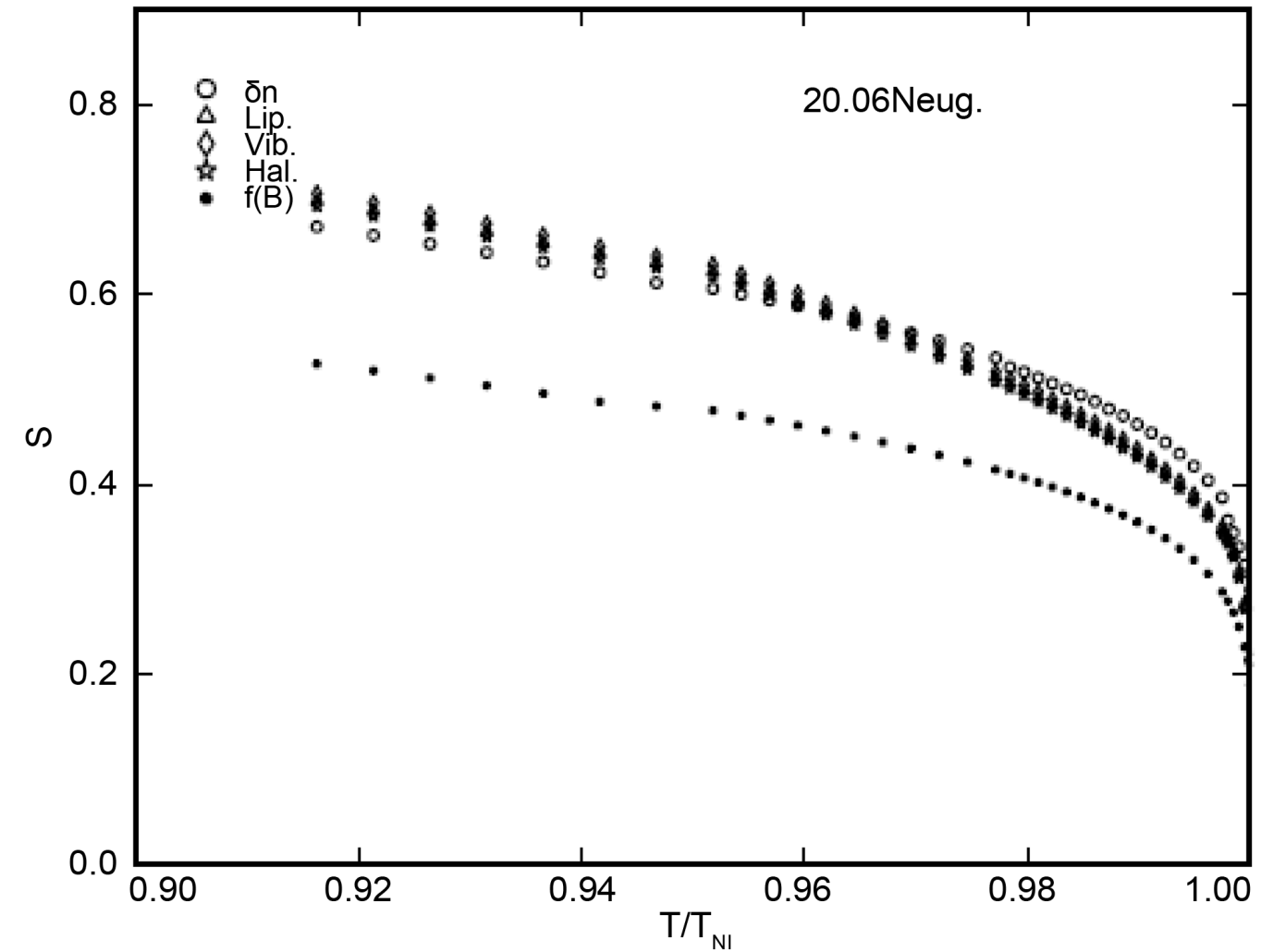

(b)

Figure 6. (a) (b) Variation of order parameter with the reduced temperature in 2O.O6. 


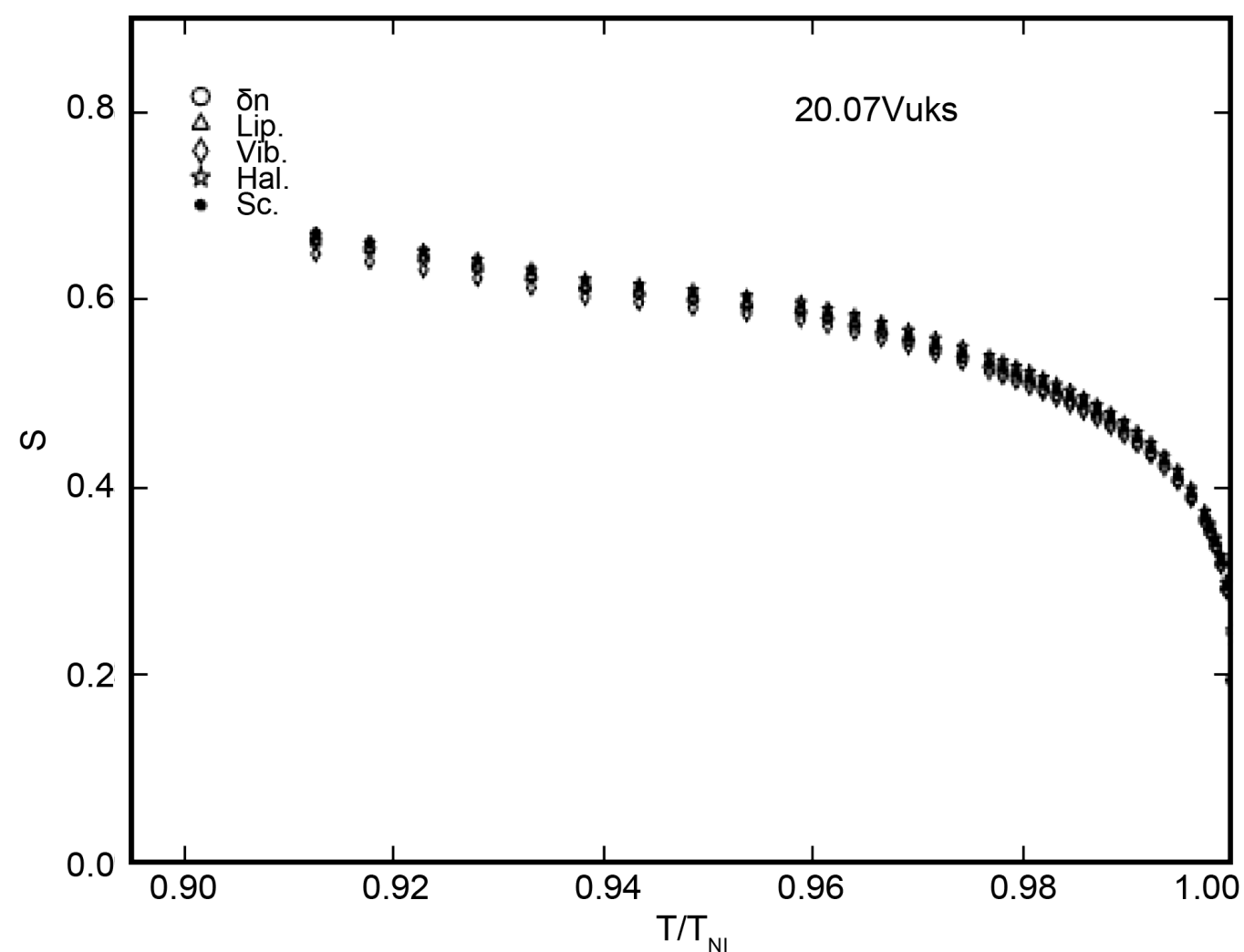

(a)

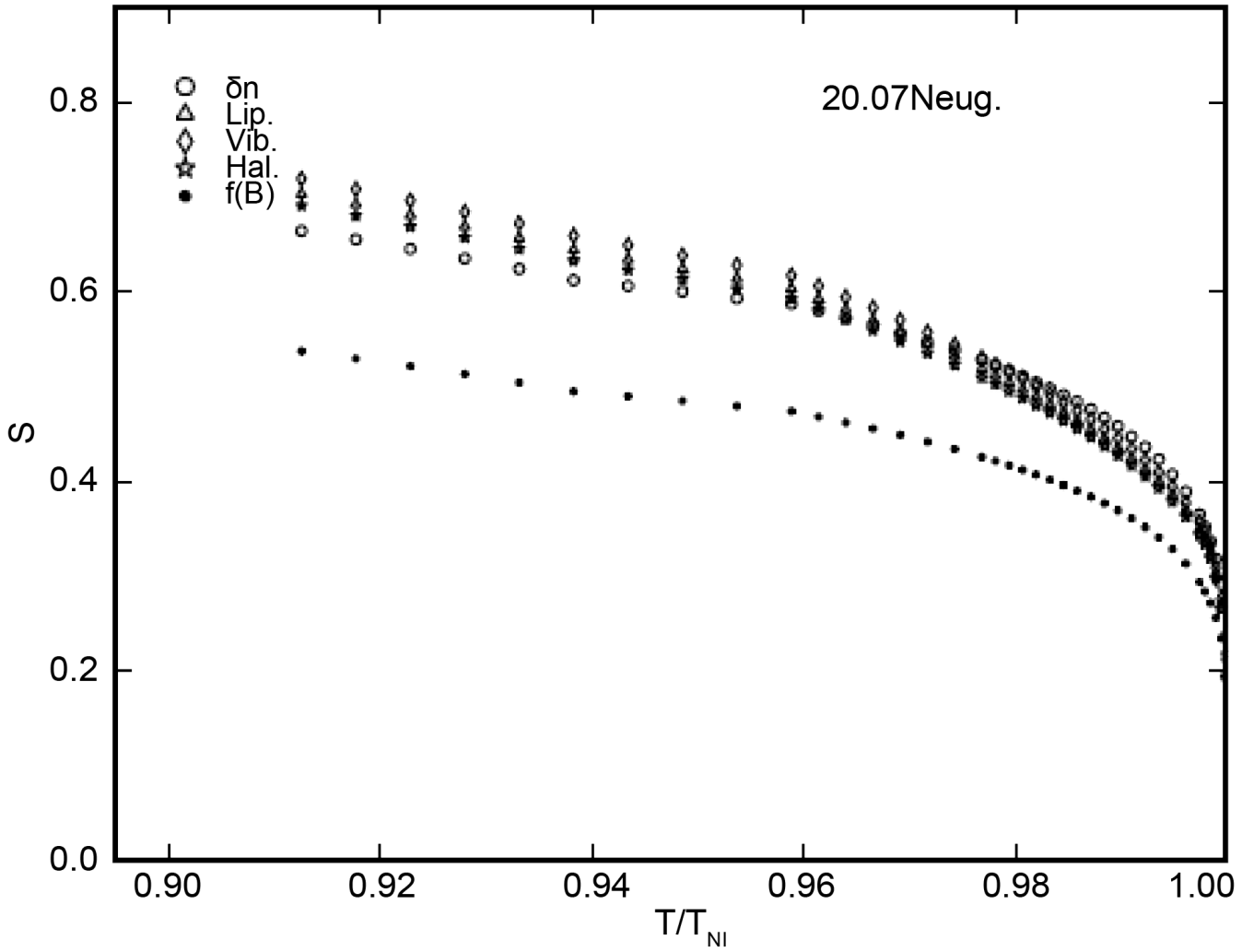

(b)

Figure 7. (a) (b) Variation of order parameter with the reduced temperature in 2O.O7. 


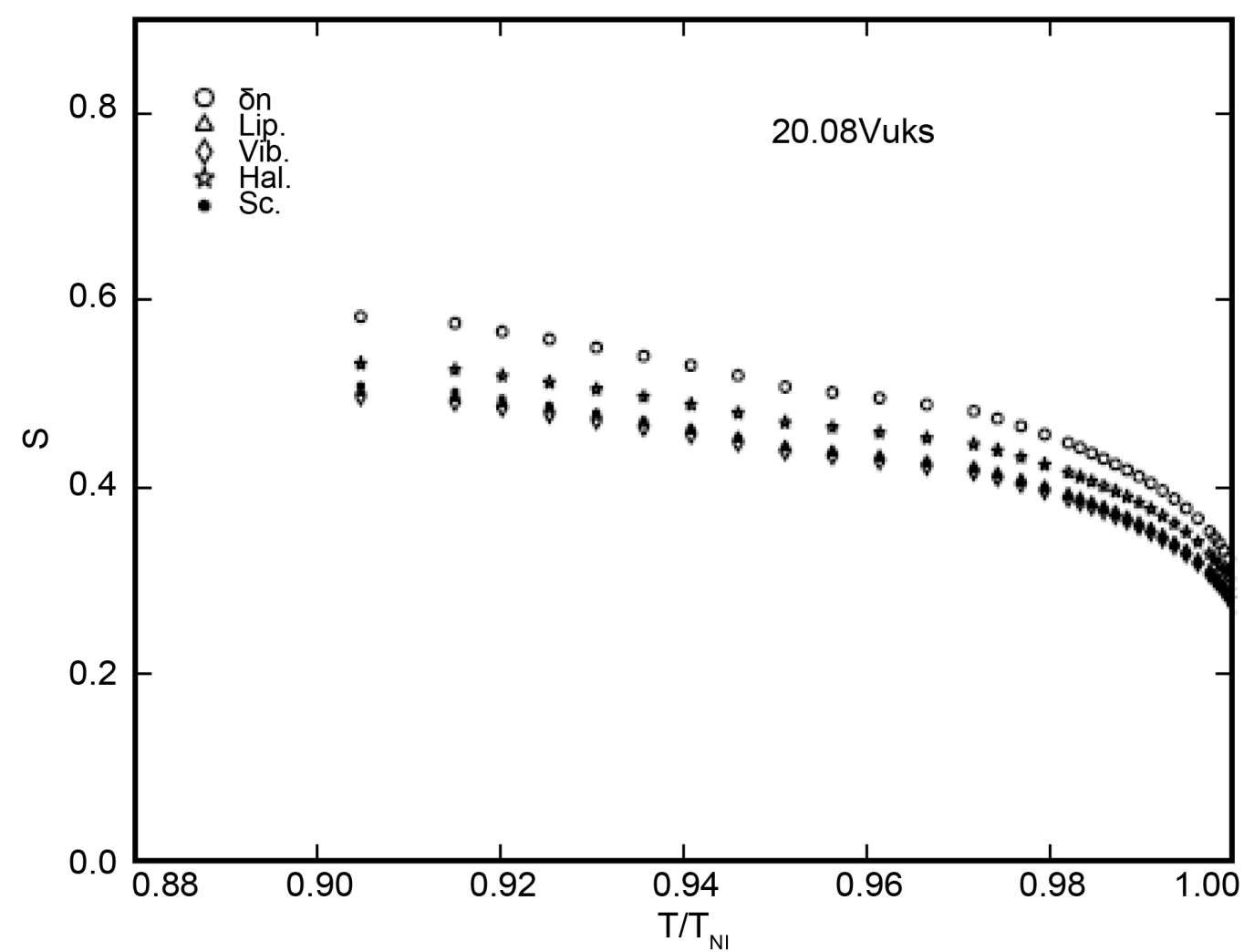

(a)

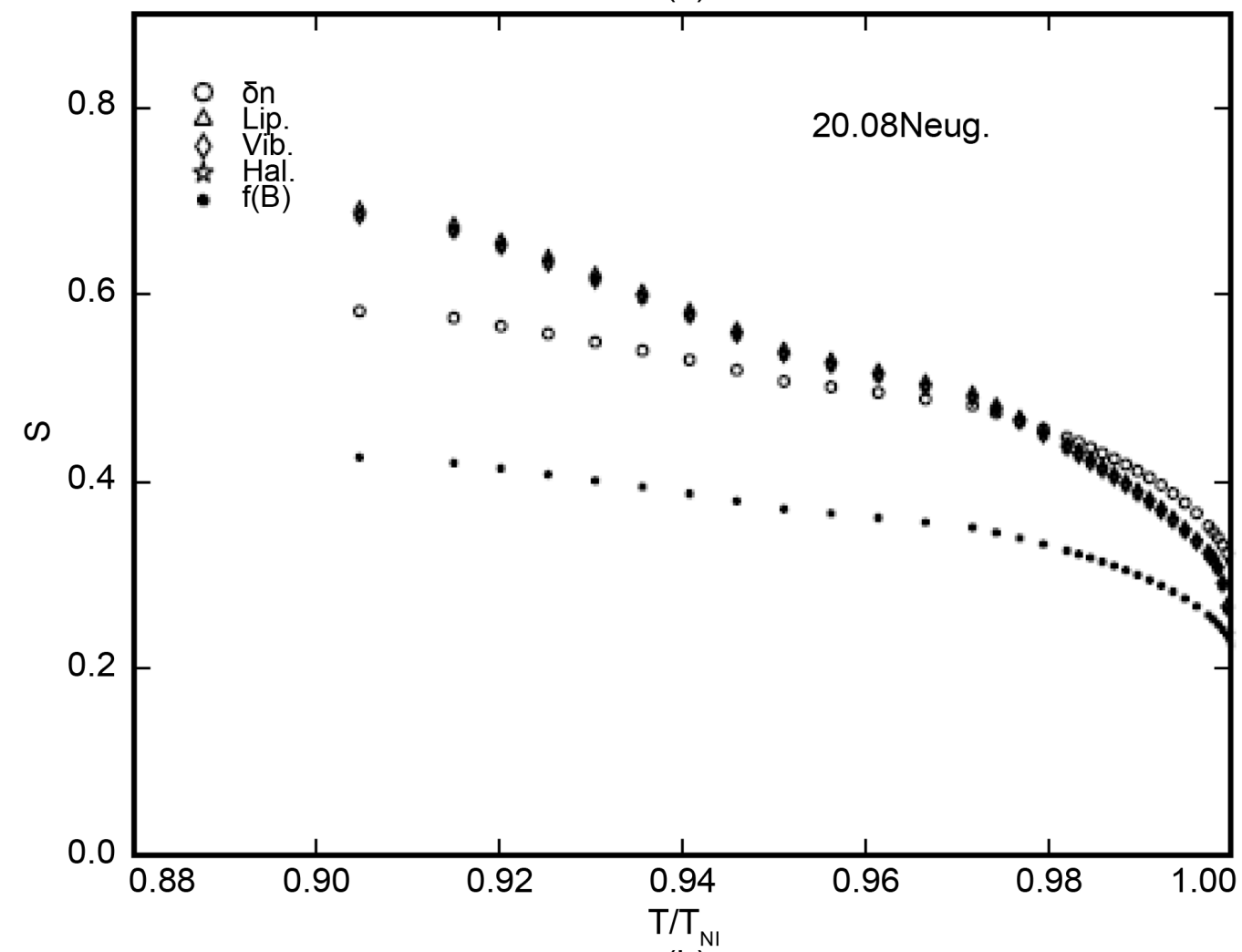

(b)

Figure 8. (a) (b) Variation of order parameter with the reduced temperature in 2O.O8. 

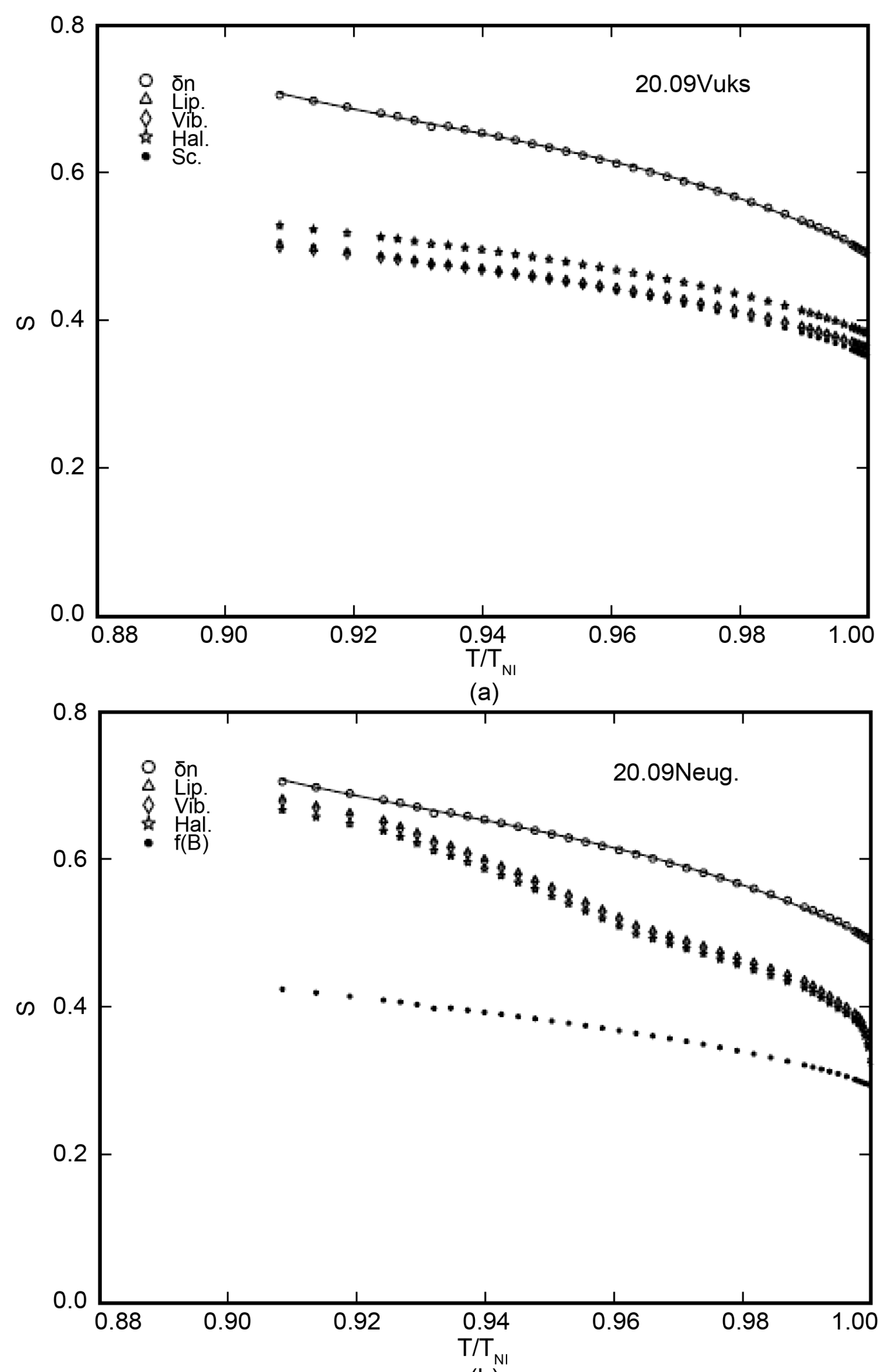

(b)

Figure 9. (a) (b) Variation of order parameter with the reduced temperature in 2O.09. 

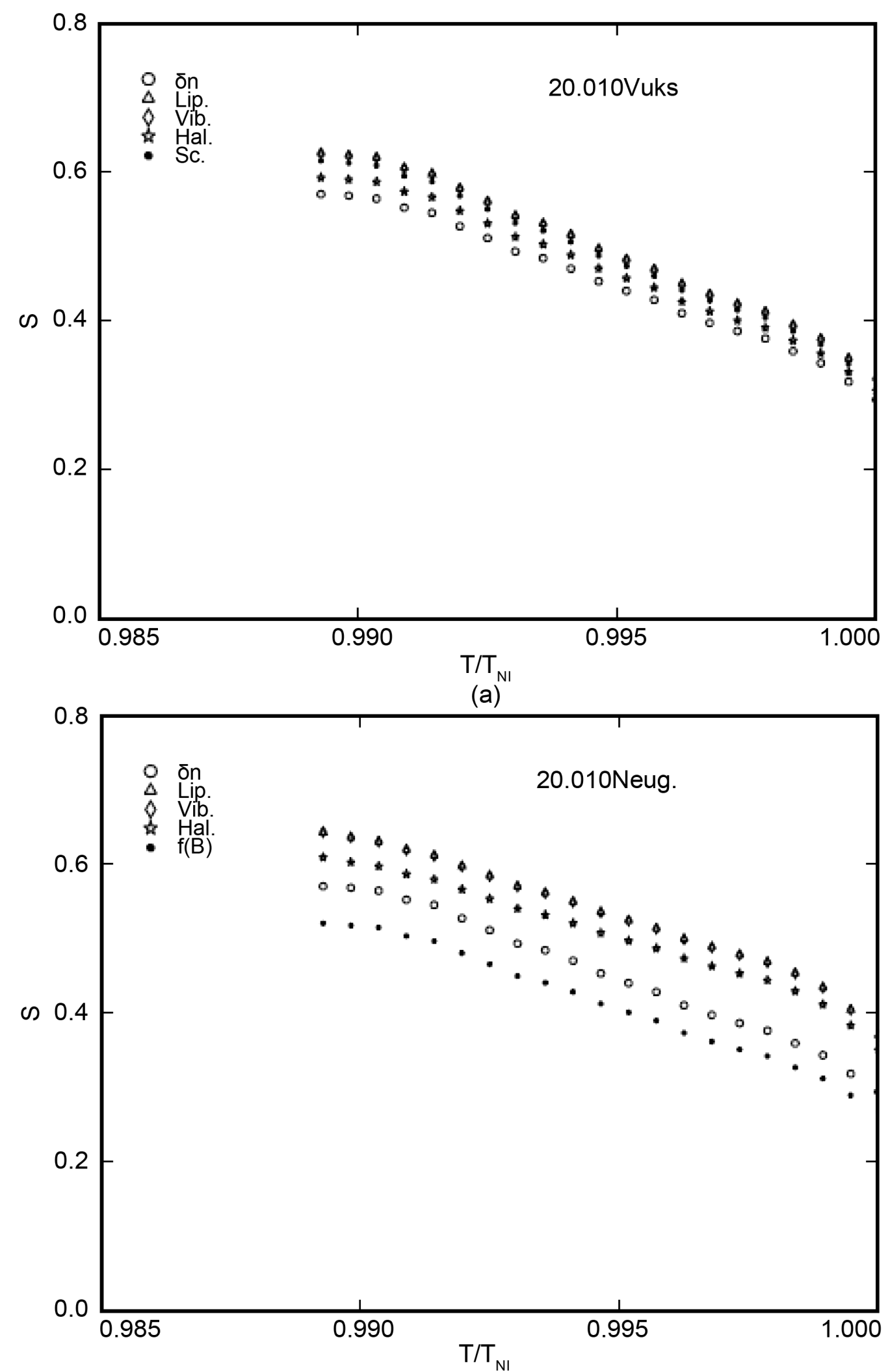

(b)

Figure 10. (a) (b) Variation of order parameter with the reduced temperature in 20.010. 


\section{Acknowledgements}

Mr. P. S. Sastry and DR. Ch. Srinivasu thank the Principal and the management of Andhra Lyola College, Vijayawada for their help. The authors Dr. P. Pardha Saradhi and Dr. V. G. K. M. Pisipati express their thank to The Head, ECE Department and the Management of K. L. University, Vaddeswaram 522 502, India for providing facilities.

\section{References}

[1] Kumar, A. (2013) Determination of Orientational Order and Effective Geometry Parameter from Refractive Indices of Some Nematics. Liquid Crystals, 40, 503-510. http://dx.doi.org/10.1080/02678292.2012.761355

[2] Hanson, E.G. and Shen, Y.R. (1976) Refractive-Indexes and Optical Anisotropy of Homologous Liquid-Crystals. Molecular Crystals and Liquid Crystals, 36, 193-207. http://dx.doi.org/10.1080/15421407608084323

[3] Kumar, A. (2007) Calculation of Optical Parameters of Liquid Crystals. Acta Physica Polonica A, 112, $1213-1221$. http://dx.doi.org/10.12693/APhysPolA.112.1213

[4] Horn, R.G. (1978) Refractive Indices and Order Parameters of Two Liquid Crystals. Journal de Physique France, 39, 105-109. http://dx.doi.org/10.1051/jphys:01978003901010500

[5] Abdulhalim, I. (1991) Dispersion Relations for the Refractive Indices and the Effective Birefringence of Liquid Crystals. Molecular Crystals and Liquid Crystals, 197, 103-108. http://dx.doi.org/10.1080/00268949108029705

[6] Li, J., Gauza, S. and Wu, S.T. (2004) Temperature Effect on Liquid Crystal Refractive Indices. Journal of Applied Physics, 96, 19-24. http://dx.doi.org/10.1063/1.1757034

[7] Pardhasaradhi, P., Prasad, P.V.D., Latha, D.M., Pisipati, V.G.K.M. and Rani, G.P. (2012) Orientational Order Parameter Studies in Two Symmetric Dimeric Liquid Crystals-An Optical Study. Phase Transitions, 85, 1031-1044.

[8] Vuks, M.F. (1966) Determination of Optical Anisotropy of Aromatic Molecules from Double Refraction in Crystals. Optics and Spectroscopy, 20, 361.

[9] Neugebauer, H.E.J. (1950) Clausius-Mosotti Equation for Certain Types of Anisotropic Crystals. Canadian Journal of Physics, 28, 292.

[10] Rao, D.V., Pardhasaradhi, P., Pisipati, V.G.K.M. and Prasad, P.V.D. (2015) Phase Transitions and Order Parameter Studies from Polarizabilities in 3.Om and 30.Om Liquid Crystalline Compounds. Molecular Crystals and Liquid Crystals. (In Press)

[11] Kelker, P. and Scheurle, B. (1969) Liquid-Crystalline (Nematic) Phase with a Particularly Liq. Solidification Point. Angewandte Chemie International Edition in English, 8, 884-885. http://dx.doi.org/10.1002/anie.196908841

[12] Haller, I., Huggins, H.A., Lilienthal, H.R. and McGuire, T.R. (1973) Order-Related Properties of Some Nematic Liquids. Journal of Physical Chemistry, 77, 950-954. http://dx.doi.org/10.1021/j100626a020

[13] Sastry, P.S., Srinivasu, Ch., Pardhasaradhi, P., Pisipati, V.G.K.M. and Prasad, P.V.D. (2016) Synthesis, Characterization and Phase Transition Studies in N-(-4-Ethyloxybenzylydene)-4'-Alkoxyanilines. Liquid Crystals, 43. (Communicated)

[14] Lippincott, E.R. and Stutma, J.M. (1965) Polarizabilities from the $\delta$-Function Model of Chemical Binding. II. Molecules with Polar Bonds. Journal of Physical Chemistry, 70, 78. http://dx.doi.org/10.1021/j100873a012

[15] Murthy, Y.N., Murthy, V.R. and Reddy, R.N.V.R. (1997) Molecular Vibration Approach to Polarizabilities of Methyl Cinnamate Liquid Crystal Compounds. Acta Physica Polonica A, 91, 1069. http://dx.doi.org/10.12693/APhysPolA.91.1069

[16] Chandrasekhar, S., Krishnamuri, D. and Madhusudana, N.V. (1969) Theory of Birefringence of Nematic Liquid Crystals. Molecular Crystals and Liquid Crystals, 8, 45.

[17] Subrahmanyam, B.H.S. and Murthi, D.K. (1973) Polarization Field and Molecular Order in Nematic Liquid Crystals. Molecular Crystals and Liquid Crystals, 22, 239. http://dx.doi.org/10.1080/15421407308083347

[18] Sekine, C., Iwakura, K., Konya, N., Minai, N. and Fujisawsa, K. (2001) Synthesis and Properties of Some Novel High Birefringence Phenylacetylene Liquid Crystal Materials with Lateral Substituents. Liquid Crystals, 28, 1375-1387. http://dx.doi.org/10.1080/02678290110059479

[19] Bell, R.P. and Long, D.A. (1950) Polarizability and Internuclear Distance in the Hydrogen Molecule and Molecule-Ion. Proceedings of the Royal Society of London A, 203, 364. http://dx.doi.org/10.1098/rspa.1950.0144

[20] Abbot, J.A. and Bolton, H.C. (1952) Electrical Polarizability as a Criterion for Molecular Wave Functions. Journal of Chemical Physics, 20, 762. http://dx.doi.org/10.1063/1.1700561 


\section{Submit or recommend next manuscript to SCIRP and we will provide best service for you:}

Accepting pre-submission inquiries through Email, Facebook, LinkedIn, Twitter, etc.

A wide selection of journals (inclusive of 9 subjects, more than 200 journals)

Providing 24-hour high-quality service

User-friendly online submission system

Fair and swift peer-review system

Efficient typesetting and proofreading procedure

Display of the result of downloads and visits, as well as the number of cited articles

Maximum dissemination of your research work

Submit your manuscript at: http://papersubmission.scirp.org/ 